\title{
Ankyrin Repeat-Rich Membrane Spanning (ARMS)/ Kidins220 Scaffold Protein Regulates Neuroblastoma Cell Proliferation through p21
}

\author{
Heekyung Jung, Joo-Hyun Shin, Young-Seok Park, and Mi-Sook Chang*
}

\begin{abstract}
Cell proliferation is tightly controlled by the cell-cycle regulatory proteins, primarily by cyclins and cyclin-dependent kinases (CDKs) in the $G_{1}$ phase. The ankyrin repeat-rich membrane spanning (ARMS) scaffold protein, also known as kinase D-interacting substrate of $220 \mathrm{kDa}$ (Kidins 220), has been previously identified as a prominent downstream target of neurotrophin and ephrin receptors. Many studies have reported that ARMS/Kidins220 acts as a major signaling platform in organizing the signaling complex to regulate various cellular responses in the nervous and vascular systems. However, the role of ARMS/Kidins220 in cell proliferation and cell-cycle progression has never been investigated. Here we report that knockdown of ARMS/Kidins220 inhibits mouse neuroblastoma cell proliferation by inducing slowdown of cell cycle in the $G_{1}$ phase. This effect is mediated by the upregulation of a CDK inhibitor p21, which causes the decrease in cyclin D1 and CDK4 protein levels and subsequent reduction of $\mathrm{pRb}$ hyperphosphorvlation. Our results suqqest a new role of ARMS/Kidins 220 as a sianaling platform to requlate tumor cell proliferation in response to the extracellular stimuli.
\end{abstract}

\section{INTRODUCTION}

The ankyrin repeat-rich membrane spanning (ARMS) protein (Kong et al., 2001), also known as a kinase D-interacting substrate of $220 \mathrm{kDa}$ (Kidins 220) (Iglesias et al., 2000), has been previously identified as a downstream interactor of neurotrophin and ephrin receptors (reviewed in Neubrand et al., 2012). As a transmembrane scaffold protein, ARMS/Kidins220 is highly expressed in the nervous system, such as hippocampus, olfactory bulb, motor neurons in the spinal cord (Iglesias et al., 2000; Kong et al., 2001). ARMS/Kidins220 is tyrosine phosphorylated specifically by Trk and Eph receptors (Kong et al., 2001). It also

Department of Oral Anatomy, School of Dentistry and Dental Research Institute, Seoul National University, Seoul 110-749, Korea

${ }^{*}$ Correspondence: mschang@snu.ac.kr

Received 30 June, 2014; revised 17 September, 2014; accepted 22 September, 2014; published online 10 November, 2014

Keywords: cell cycle, cyclin, neurotrophin, proliferation, scaffold protein directly interacts with all three Trk receptors and with p75NTR to form a ternary complex (Arevalo et al., 2004; Chang et al., 2004). Accordingly, ARMS has many important functions in the nervous system, such as neuronal survival (Duffy et al., 2011; Lopez-Menendez et al., 2009; Sniderhan et al., 2008), cytoskeletal remodeling and neuronal differentiation (Bracale et al., 2007; Higuero et al., 2010; Neubrand et al., 2010; Park et al., 2010), dendrite and synapse development (Chen et al., 2012; Cortes et al., 2007; Wu et al., 2009) and neuronal activity and synaptic plasticity (Arevalo et al., 2010; Cesca et al., 2012; Sutachan et al., 2010; Wu et al., 2010).

Interestingly, ARMS/Kidins220 acts as a signaling platform for sustained activation of the mitogen-activated protein kinase (MAPK) signaling through the recruitment of CrkL-C3G complex and Rap1 (Arevalo et al., 2004; 2006). Since MAPK signaling is a major survival pathway and Trk receptors were initially identified as oncogenes (Martin-Zanca et al., 1986), ARMS/ Kidins220 has also been suggested as a potential oncogene (Neubrand et al., 2012). ARMS/Kidins220 is highly expressed in melanoma, and it contributes to melanoma progression by sustained MAPK signaling and inhibiting stress-induced apoptosis (Liao et al., 2007). Recently, it is also reported that ARMS/Kidins220 is expressed in human neuroblastoma cells and stabilizes NGF-induced survival signaling (Rogers and Schor, 2013).

Although ARMS/Kidins220 is involved in tumor cell survival and contributes to tumor progression, its role in cell proliferation and cell-cycle progression has never been investigated. In this study, we report that knockdown of ARMS/Kidins220 in mouse neuroblastoma cells induces a slowdown of cell cycle in the $G_{1}$ phase, which results in a decrease in cell proliferation. The $G_{1}$ phase arrest is associated with the decreased expressions of cyclin D1 and cyclin-dependent kinase 4 (CDK4) and hyperphosphorylated $\mathrm{pRb}$, which is mediated by $\mathrm{p} 21$ upregulation. Thus, the p21-cyclinD1/CDK4 signaling pathway plays a critical role in ARMS/Kidins220-dependent cell-cycle progression. Taken together, our study reveals a novel mechanism by which ARMS/ Kidins220 scaffold protein regulates tumor cell proliferation.

\section{MATERIALS AND METHODS}

\section{Cell culture}

Neuro2a mouse neuroblastoma cells were grown in Dulbecco's modified Eagle's medium (DMEM; Hyclone) supplemented with $10 \%$ fetal bovine serum (FBS; Gibco), $10 \mathrm{U} / \mathrm{ml}$ penicillin, and $10 \mathrm{~g} / \mathrm{ml}$ streptomycin at $37^{\circ} \mathrm{C}$ with $5 \% \mathrm{CO}_{2}$. 


\section{Antibodies}

The following antibodies were used: rabbit polyclonal (clone 892) against the C-terminus of ARMS/Kidins220 (Kong et al., 2001); cyclin D1, cyclin A, cyclin E, CDK4, ERK, pERK and phospho-pRb (Ser780) (Cell Signaling); CDK2, p21, p16 and $\alpha-$ tubulin (Sigma).

Generation of ARMS/Kidins220 short hairpin RNA (shRNA) retroviral vectors and ARMS/Kidins220-knockdown Neuro2a cell lines

Retroviral vectors producing shRNA against ARMS/Kidins220 were constructed by inserting oligonucleotide sequence $5^{\prime}$ CACCGCCAGAGAGCAGATCAGTATTCGAAAATACTGATCT GCTCTCTGGC-3' (forward) and 5'-AAAAGCCAGAGAGCAGATCAGTATITTCGAATACTGATCTGCTCTCTGGC'-3' (reverse) (Li et al., 2008) into pSuper.retro vector (OligoEngine) as previously described (Brummelkamp et al., 2002). Briefly, the pSUPER.retro vector with shARMS sequences was cotransfected with VM- $\gamma \mathrm{P}$ and VSV-G plasmids into 293T cells using Lipofectamine (Invitrogen) according to the manufacturer's protocol. After $48 \mathrm{~h}$, the culture media were filtered through a $0.45 \mu \mathrm{m}$ filter (Satorius) to obtain retroviral supernatants. To obtain highly concentrated virus stock, the supernatant was ultra-centrifuged at $250,000 \times g$ for $1.5 \mathrm{~h}$ at $4^{\circ} \mathrm{C}$ using a Beckman SW26 rotor. Virus pellets were re-suspended in a small amount ( $1 \%$ of original volume) of serum-free DMEM. Titration of virus was performed using NIH3T3 cells infected with 10 -fold serial dilutions and virus titer was determined at day 5 post-inoculation by counting the number of puromycin (2 $\mu \mathrm{g} / \mathrm{ml}$ )-resistant colonies. To construct the control and ARMS/ Kidins220-knockdown Neuro2a stable cell lines, Neuro2a cells were infected with retroviral supernatants containing $4 \mu \mathrm{g} / \mathrm{ml}$ polybrene for $5 \mathrm{~h}$. After adsorption, cells were allowed to recover for $48 \mathrm{~h}$ in DMEM containing 10\% FBS and cultured in selection media containing puromycin $(2 \mu \mathrm{g} / \mathrm{ml})$ for next 7 days.

\section{Cell proliferation assay}

For the cellular growth assay, cells were plated in 24-well plates $\left(5 \times 10^{3}\right.$ cells/well $)$ and counted at the indicated time points after being trypsinized and incubated with trypan blue solution (Gibco). The cell proliferation was also measured using EZCyTox (Daeil Science, Korea) according to the manufacturer's protocol. Cells were plated in 96 -well plates $\left(3 \times 10^{3}\right.$ cells/well), and $10 \mu \mathrm{l}$ of assay solution were added to each well. Cells were then incubated for $1.5 \mathrm{~h}$ at $37^{\circ} \mathrm{C}$, and the absorbance was measured at $450 \mathrm{~nm}$ using a microplate reader (Bio-Rad).

\section{Fluorescence-activated cell sorting analysis}

The cell-cycle profile was measured by flow cytometry using propidium iodide $(\mathrm{PI}$; Sigma) at indicated times $(0,24$, and 48 h). Briefly, trypsinized cells were collected by centrifugation, washed twice with cold PBS, fixed with cold $70 \%$ methanol drop-wise while vortexing gently, and then left on ice at least 1 h. After washing twice with PBS, DNA was stained with 50 $\mu \mathrm{g} / \mathrm{ml} \mathrm{PI}$ and $0.1 \mathrm{mg} / \mathrm{ml}$ RNase A (Sigma) for $30 \mathrm{~min}$ in the dark (Jadhav et al., 2007). The DNA content of the nuclei was analyzed using a FACS Calibur system (Becton Dickinson). Cell cycle distribution was analyzed with ModFit LT ${ }^{\mathrm{TM}}$ software (Becton Dickinson).

\section{Immunoblotting}

To synchronize cells in the Go phase, cells were cultured in serum-free DMEM for $24 \mathrm{~h}$ and then stimulated to enter the cell cycle in DMEM containing 10\% FBS. For immunoblotting, cell lysates were prepared at the indicated times $(0,4,8$ and $24 \mathrm{~h}$ ). Briefly, cells were rinsed with ice-cold PBS twice, and were harvested in $10 \mathrm{mM}$ Tris- $\mathrm{HCl}(\mathrm{pH} 8.0), 150 \mathrm{mM} \mathrm{NaCl}$, $1 \mathrm{mM}$ EDTA, and 1\% NP-40 (TNE buffer) containing protease and phosphatase inhibitors. Equal amount of proteins (100 $\mu \mathrm{g} / \mathrm{lane}$ ) were resolved by $6-20 \%$ gradient SDS-PAGE, and western blotting was performed with antibodies against different proteins.

\section{Statistical analysis}

Data were analyzed using Student's $t$-test and expressed as mean \pm standard error of mean (SEM). Probability $(P)$ values < 0.05 were considered statistically significant.

\section{RESULTS}

Downregulation of ARMS/Kidins220 results in decreased neuroblastoma cell proliferation

The expression of ARMS/Kidins220 in melanoma cells has been shown to confer resistance to UVB-induced apoptosis by activating ERK signaling pathway (Liao et al., 2007). Despite the fact that ARMS is a potential oncogene and is involved in tumor cell survival signaling (Liao et al., 2007; 2011), little is known about its effects on tumor cell proliferation. Thus, in this study, we sought to examine the role of ARMS/Kidins220 in tumor cell proliferation.

First, we established ARMS/Kidins220-knockdown Neuro2a stable cell lines (ARMS-KD) using ARMS-specific shRNA (shARMS)-containing retroviral vectors. Control Neuro2a cells were infected with a virus containing vector alone. We confirmed that ARMS/Kidins220 expression was reduced to $35.9 \pm$ $2 \%$ in ARMS-KD cells compared with the control cells (Fig. 1A). Next, we performed cell proliferation assay using trypan blue staining to investigate whether ARMS/Kidins220 can regulate proliferation in these cells. The control and ARMS-KD cells were synchronized in the Go phase by serum starvation for 24 h. They passed through the cell cycle after the addition of $10 \%$ FBS. Cell proliferation was inferred by the number of cells at the indicated times. As shown in Fig. 1B, there was no statistical difference in cell growth between the two cell lines on the 1st day. However, on the 2nd day, the number of cells in the control was significantly higher than the number of ARMS-KD cells. On the 4th day, there were 1.82 times more control cells than ARMS-KD cells (Control, $24 \times 10^{3} \pm 0.24$ vs ARMS-KD, $13.8 \times 10^{3} \pm 0.11$ ). The doubling times of control and ARMS-KD cells are approximately 1.88 days and 4.26 days, respectively.

To confirm the previous result, we also examined cell proliferation using EZ-CyTox assay. As expected from the results of the cell counting assay, ARMS-KD cells showed decreased proliferation compared to the control cells on the 2 nd day, with maximal apparent differences on the 4th day (Control, $2.01 \pm 0.08$ vs ARMS-KD, $1.03 \pm 0.07$ ) (Fig. 1C). Taken together, these data suggest that the expression level of ARMS/ Kidins220 influences on the proliferation of Neuro2a cells.

Downregulation of ARMS/Kidins220 results in a prolonged G1 phase of the cell cycle

To investigate whether the effect of ARMS/Kidins220 on neuroblastoma cell growth is due to alteration of the cell cycle, we analyzed cell-cycle phase progression using fluorescenceactivated cell sorting (FACS) on the control and ARMS-KD cells (Fig. 2A). Cells were synchronized in the Go phase of cell cycle by serum starvation for $24 \mathrm{~h}$. There were no significant differences in the proportion of both cells in the all phases of cell 
A

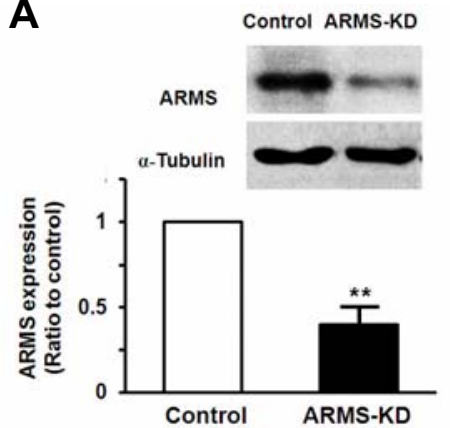

B

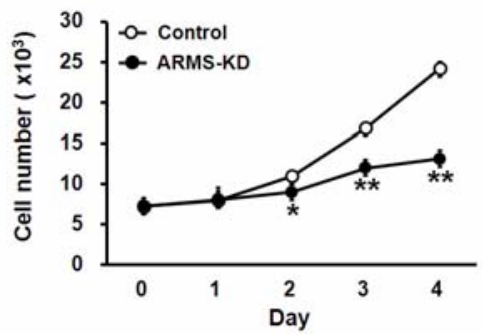

C

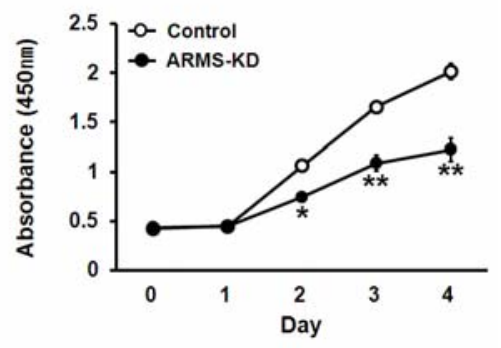

Fig. 1. Downregulation of ARMS/Kidins220 inhibits Neuro2a cell proliferation. (A) Western blot analysis of Neuro2a cell lysates after shControl and shARMS retroviral infection. To verify the reduction of ARMS/Kidins220 protein expression, Western blotting was performed with ARMS/Kidins220 (892) antibody and $\alpha$-tubulin antibody. (B) Cell counting assay for cell proliferation. Cell proliferation was determined by counting the cell number with trypan blue staining at the indicated times. (C) Cell proliferation assay. On each day, the cells were incubated with EZ-CyTox solution for $1.5 \mathrm{~h}$ and the absorbance was measured using an ELISA reader at $450 \mathrm{~nm}$. The values are represented as the mean \pm SEM of three independent experiments, and statistical significance is evaluated by Student's $t$-test $\left({ }^{*} p<0.05,{ }^{* *} p<0.01\right)$.

A

on

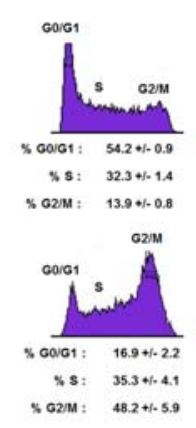

$48 \mathrm{~h}$

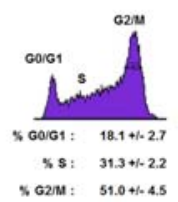

B

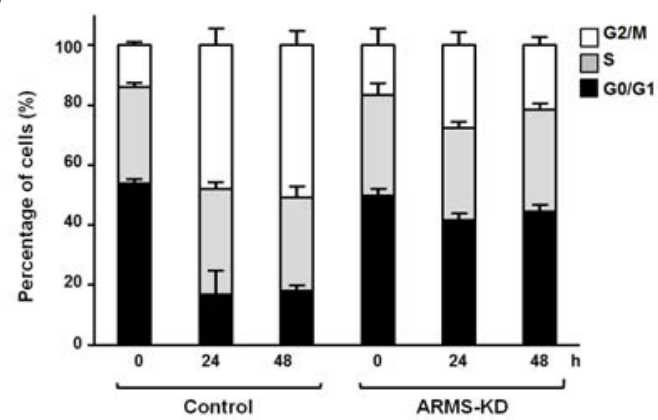

Fig. 2. Downregulation of ARMS/Kidins220 inhibits cell cycle progression in the $\mathrm{Go}_{\mathrm{O}} \mathrm{G}_{1}$ phase. After Go synchronization in serumfree DMEM for $24 \mathrm{~h}$, the control and ARMS-KD neuroblastoma cells were cultured with DMEM containing $10 \%$ FBS to stimulate re-entry into the cell cycle. (A) FACS analysis in the control and ARMS-KD cells. At each time point, cells were fixed, stained with propidium iodide (PI), and analyzed for DNA content by the flow cytometry. The distribution of cells in $\mathrm{Go}_{0} \mathrm{G}_{1}, \mathrm{~S}$, and $\mathrm{G}_{2} / \mathrm{M}$ phase is indicated. (B) The bar graph shows the percentage of the cells in $G_{0} / G_{1}, S$, and $G_{2} / M$ phase in the control and ARMS-KD cells. The values are represented as the mean \pm SEM of three independent experiments. cycle at $0 \mathrm{~h}$. However, at $24 \mathrm{~h}$ after the addition of $10 \%$ FBS, the proportion of the control cells in the $\mathrm{Go}_{\mathrm{G}} \mathrm{G}_{1}$ phase significantly decreased from $54.2 \pm 0.9 \%$ to $16.9 \pm 2.2 \%$, whereas the proportion of ARMS-KD cells in the $\mathrm{Go} / \mathrm{G}_{1}$ phase decreased from $50.0 \pm 2.1 \%$ to $41.7 \pm 0.4 \%$ (Fig. $2 B$ ). At the same time, the proportion of control cells in the $\mathrm{G}_{2} / \mathrm{M}$ phase dramatically increased from $13.9 \pm 0.8 \%$ to $48.2 \pm 5.9 \%$, whereas the proportion of ARMS-KD cells in the $\mathrm{G}_{2} / \mathrm{M}$ phase increased from $16.8 \pm 2.4 \%$ to $27.7 \pm 2.9 \%$ (Fig. $2 \mathrm{~B}$ ). These results suggest that downregulation of ARMS/Kidins220 induced a slowdown of cell cycle in the $G_{1}$ phase, leading to retarded cell growth.

Downregulation of ARMS/Kidins220 is associated with the decreased levels of cyclin D1 and CDK4

Cell growth is controlled by the expression and activity of cellcycle regulatory proteins, such as cyclins and CDKs. D-type cyclins are important for cell-cycle progression through the $G_{1}$ phase (Sherr, 1995). Decreased cyclin D1 expression prevents cells from entering the $S$ phase, leading to cell-cycle arrest in the $\mathrm{G}_{1}$ phase (Baldin et al., 1993). Since downregulation of ARMS/Kidins220 induced $G_{1}$ phase arrest, we performed Western blotting to examine the expression of the $G_{1}$ phase regulatory protein, cyclin $\mathrm{D} 1$, at the different time points of cell cycle progression. Downregulation of ARMS/Kidins220 resulted in significant decreases in cyclin D1 protein levels at 8, 24 and $48 \mathrm{~h}$, when compared with control cells $(p<0.01)$ (Figs. 3A and $3 \mathrm{~B}$ ). Although there was some decrease in cyclin D1 protein levels at $0 \mathrm{~h}$ in ARMS-KD cells, this decrease did not reach statistical significance.

To examine the effects of ARMS/Kidins220-knockdown on the other types of cyclins, we also analyzed the expression of cyclin $E$ and cyclin $A$ in both cells. Cyclin $E$ is involved in the $S$ phase, and cyclin A mainly functions in $\mathrm{G}_{2} / \mathrm{M}$ phase (Furuno et al., 1999). In contrast to cyclin D1, there were no significant differences in cyclin $E$ and cyclin $A$ expressions between the control and ARMS-KD cells (Figs. 3A, 3C, and 3D).

We next examined the kinase partner of each cyclin at different time points. Downregulation of ARMS/Kidins220 resulted in significant decreases in the protein levels of CDK4, the kinase partner of cyclin D1, at the all-time points $(p<0.01)$ (Figs. 3A and $3 \mathrm{E}$ ). Interestingly, even at $0 \mathrm{~h}$, without cell-cycle progresssion, CDK4 protein level was significantly decreased in ARMS$\mathrm{KD}$ cells. In contrast, the expression of CDK2, the kinase part- 


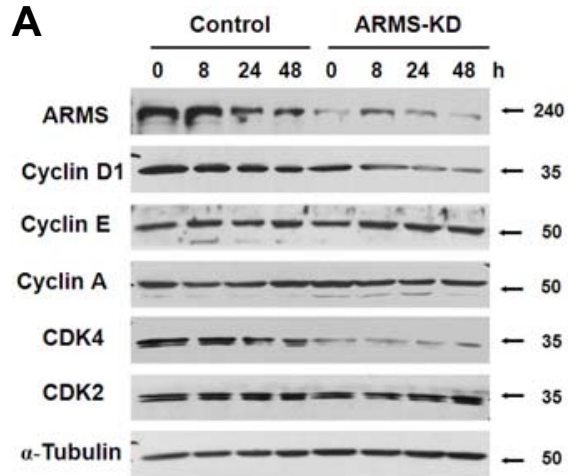

B

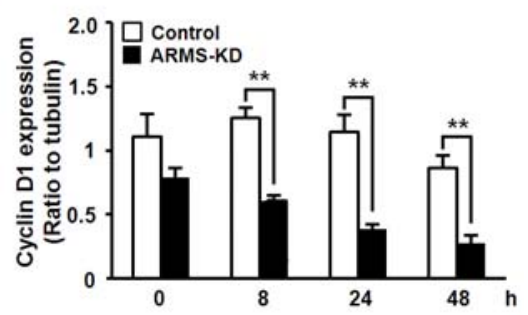

C

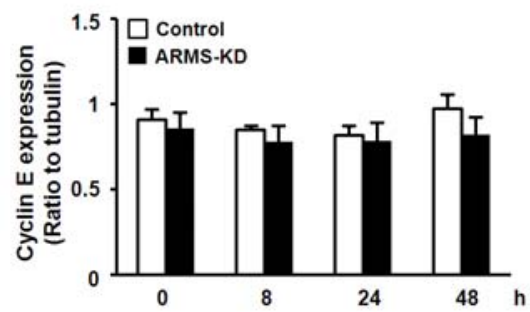

E

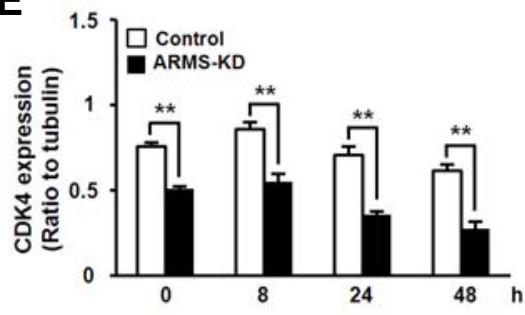

D

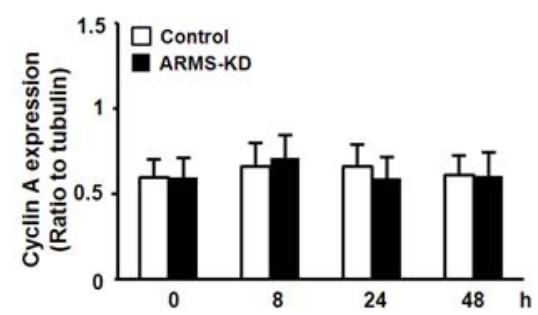

$\mathbf{F}$

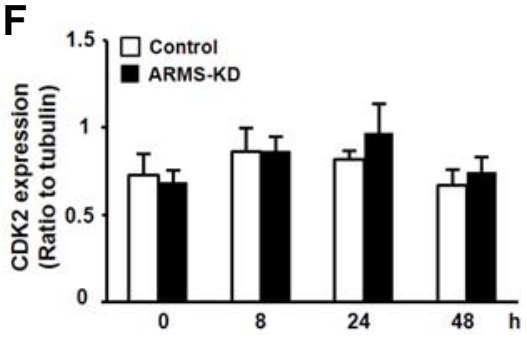

Fig. 3. Downregulation of ARMS/Kidins220 is associated with the decreased levels of cyclin D1 and CDK4. After Go synchronization in serum-free DMEM for $24 \mathrm{~h}$, the control and ARMS-KD neuroblastoma cells were cultured with DMEM containing $10 \%$ FBS to stimulate re-entry into the cell cycle. (A) Western blot analysis of cyclins and CDKs in the control and ARMS-KD neuroblastoma cells at 0,8 , 24, $48 \mathrm{~h}$ after re-entry into the cell cycle. The loading control is $\alpha$-tubulin. (B-F) Band intensities from three independent experiments were analyzed and normalized to $\alpha$-tubulin The values are mean \pm SEM and statistical significance was evaluated by Student's $t$-test $\left({ }^{*} p<0.05,{ }^{* *} p<0.01\right)$. ner of cyclin $E$ and cyclin A, was similar in both cells (Fig. 3F). These results indicate that knockdown of ARMS/Kidins220 is associated with the decreased expressions of cyclin D1 and CDK4 in the $G_{1}$ phase but has no effect on other cell cycle regulatory proteins.

Downregulation of ARMS/Kidins220 inhibits the hyperphosphorylation of $\mathrm{pRb}$ via reduction of cyclin D1 and CDK4 To confirm whether the reduction of cyclin D1 and CDK4 causes an effect on the downstream pRb pathway, we performed Western blotting with a phospho-pRb (Ser780) antibody, which specifically binds to CDK4-phosphorylated $\mathrm{pRb}$. pRb hyperphosphorylation occurs at each $\mathrm{G}_{1} / \mathrm{S}$ transition in both normal and cancer cells, and Ser780 of pRb is a site phosphorylated specifically by CDK4 (Chen et al., 1989; Jiao et al., 2006). As expected, the level of hyperphosphorylated $p R b(p p R b)$ was lower in ARMS-KD cells than the control cells at $24 \mathrm{~h}$ although there is no difference between the two cells at earlier time points $(0,4,8 \mathrm{~h})$ (Fig. 4D). This result suggests that reduction of cyclin D1 and CDK4 decreases pRb phosphorylation, which in turn leads to a slowdown of cell cycle in the $G_{1}$ phase (Figs. 4A4D).

To further confirm the role of ARMS/Kidins220 in regulation of cyclin D1/CDK4, we analyzed the expression of cyclindependent kinase inhibitors (CKIs) in $\mathrm{G}_{1} / \mathrm{S}$ transition, p21 and p16. p21 is involved in regulating the function of cyclin D1/CDK4 and cyclin E/CDK2 complexes (El-Deiry et al., 1993;
Harper et al., 1993; Xiong et al., 1993a). Another CKI protein p16 specifically inhibits the function of cyclin D1/CDK4 in the $G_{1}$ phase (Bates et al., 1994; Xiong et al., 1993b). At all-time points in our experiment, the levels of p21 protein in ARMS-KD cells were significantly higher than the control cells (Fig. 4E). In contrast, there was no difference in the levels of p16 protein between the two cells (Fig. 4F). These results indicate that knockdown of ARMS/Kidins220 upregulates p21 protein expression, thus inhibiting cyclin D1/CDK4 function in the $G_{1}$ phase of cell cycle.

Next, we examined the p42- and p44-kDa extracellular signalregulated kinases (ERKs) activation in ARMS-KD cells since ARMS/Kidins220 was proven to act as a platform for sustained Erk activation in neurons through the recruitment of CrkL (Arevalo et al., 2004; 2006) and ARMS/Kidins220-knockdown downregulates ERK activity in melanoma cells (Liao et al., 2007; 2011). Consistent with the previous studies, the level of $p E R K$ protein in ARMS-KD cells was decreased at early time points compared with the control cells, especially at $60 \mathrm{~min}(p<0.05)$ (Supplementary Fig. 1). We also observed the level of pERK protein in both cells at $4,8,24 \mathrm{~h}$. The level of pERK protein in ARMS-KD cells was significantly decreased at $24 \mathrm{~h}$ when compared with the control cells $(p<0.05)$ (Figs. 4A and $4 G$ ).

Taken together, our results suggest that downregulation of ARMS/Kidins220 inhibits cell-cycle progression at $G_{1} / S$ check point through the upregulation of p21 protein in neuroblastoma cells (Fig. 5). 
A
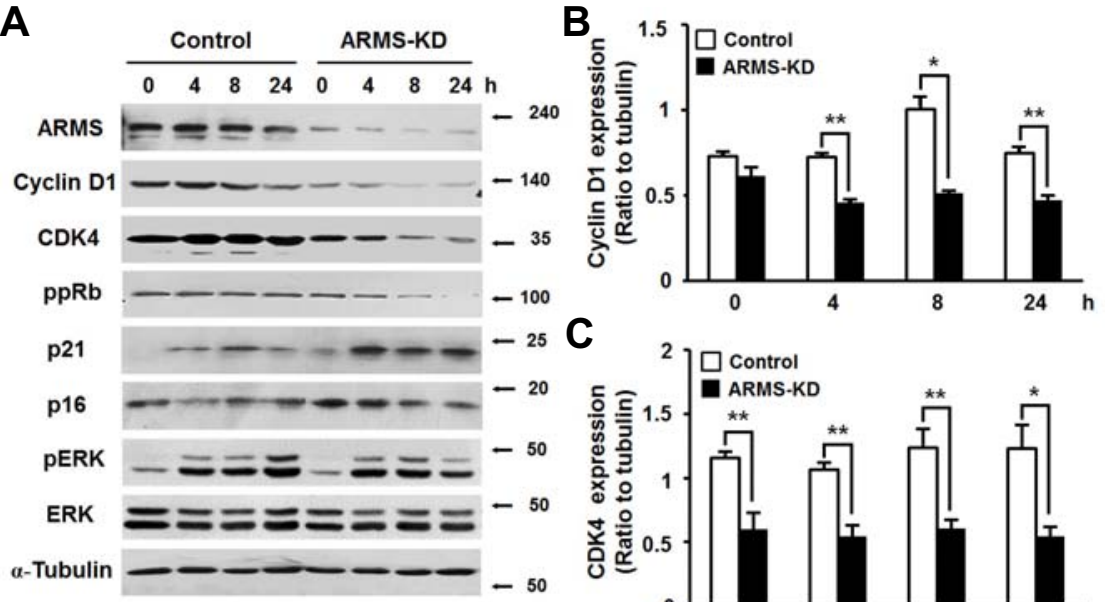

C
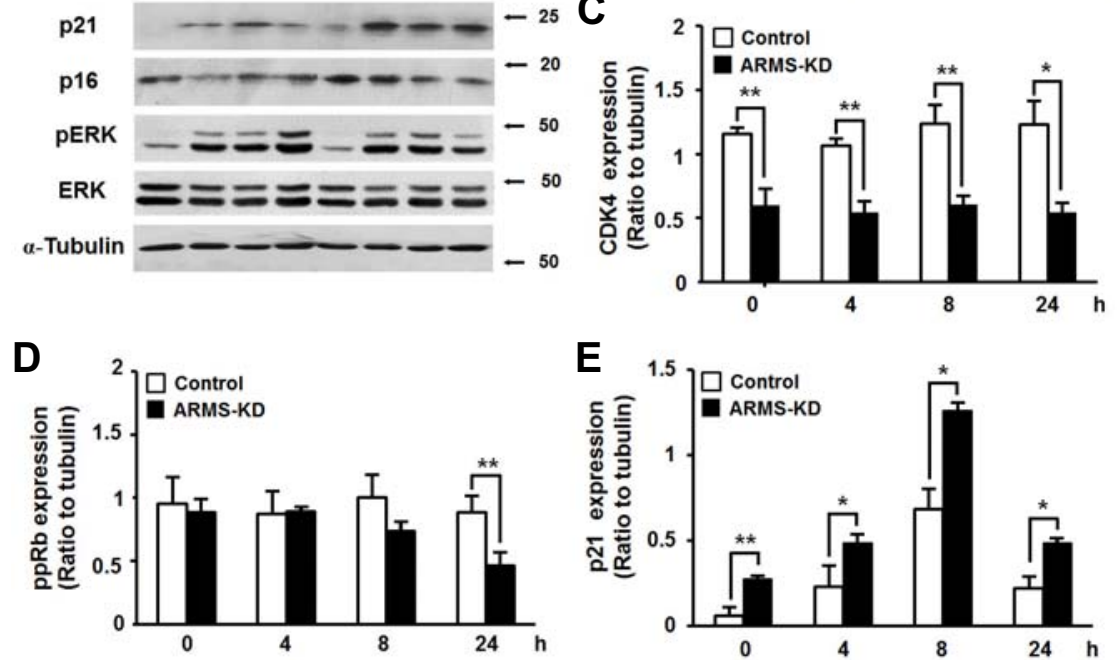

$\mathbf{F}$

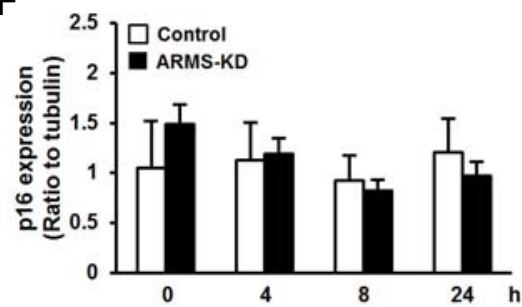

E

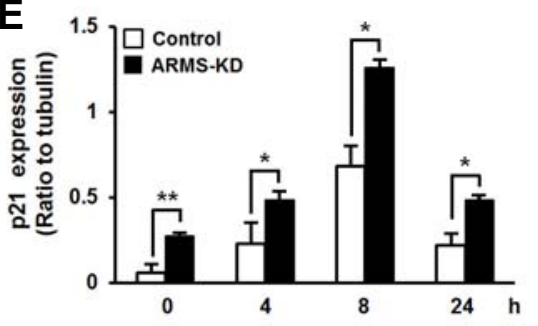

G

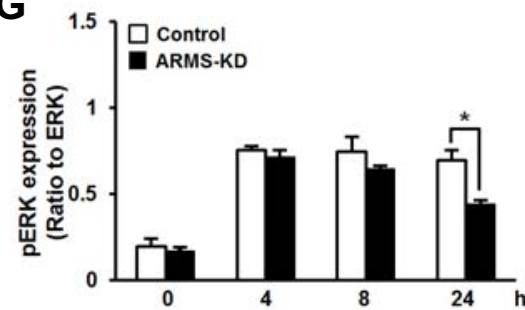

Fig. 4. Downregulation of ARMS/Kidins220 is associated with the decreased levels of $\mathrm{ppRb}$ and $\mathrm{pERK}$, and the increased levels of p21. After Go synchronization in serumfree DMEM for $24 \mathrm{~h}$, the control and ARMS$\mathrm{KD}$ neuroblastoma cells were cultured with DMEM containing $10 \%$ FBS to stimulate reentry into the cell cycle. (A) Western blot analysis of cyclin D1, CDK4, ppRb, p21, p16, pERK and ERK in the control and ARMS-KD neuroblastoma cells at $0,4,8$, $24 \mathrm{~h}$ after re-entry into the cell cycle. The loading control is $\alpha$-tubulin. (B-G) The bar graphs show the changes in cyclin D1, CDK4, ppRb, p21, p16, pERK and ERK during cell cycle progression in the control and ARMS-KD cells. Band intensities from three independent experiments were analyzed and normalized to $\alpha$-tubulin. The values are mean \pm SEM and statistical significance was evaluated by Student's $t$-test ( ${ }^{*} p$ $<0.05,{ }^{* *} p<0.01$ ).

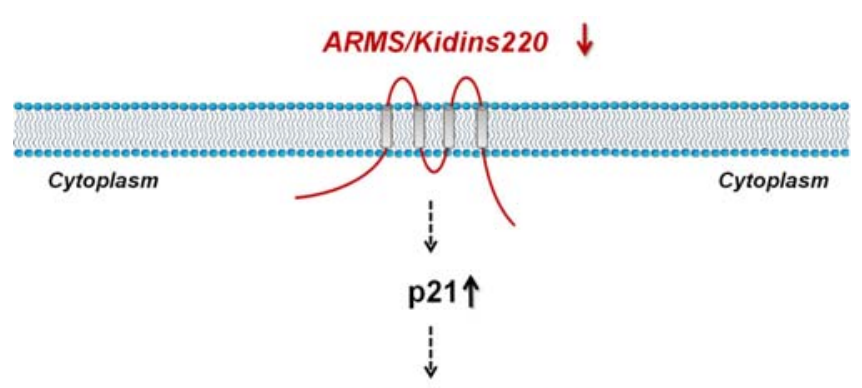

Cyclin D1/CDK4 $\downarrow$
Fig. 5. Diagram depicting how ARMS/Kidins220 regulates cellcycle progression. ARMS/Kidins220-knockdown upregulates p21 protein expression, which in turn reduces the levels of cyclin D1 and CDK4 in $G_{1}$ phase. Inhibition of cyclin D1 and CDK4 results in the increased level of hypophosphorylated $\mathrm{pRb}$ and subsequent sequestration of E2F transcription factors. The transcriptional activation of E2F-responsive genes is essential for DNA synthesis and cell cycle progression. Taken together, reduction of ARMS/Kidins220 expression upregulates p21 expression, leading to inhibition of cyclin D1 and CDK4, and reducing $\mathrm{pRb}$ hyperphosphorylation.

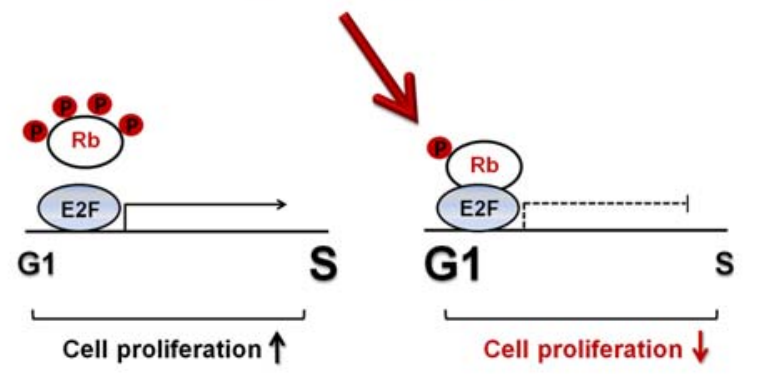




\section{DISCUSSION}

ARMS/Kidins220 is a transmembrane protein highly expressed in the nervous system, and has critical roles in neuronal differentiation, survival and development. As a multifunctional scaffold protein, it has various domains for protein-protein interactions (Iglesias et al., 2000; Kong et al., 2001). Thus ARMS/Kidins220 has been suggested to play important roles in organizing the assembly of protein complexes of receptors and effectors which transduce the extracellular stimuli to signaling pathways inside the cell (Chao, 2003; Neubrand et al., 2012). Accordingly, there is an increasing body of evidence that ARMS/Kidins220 has various physiological functions not only in the nervous system but also in the vascular system (Cesca et al., 2012)

However, the pathological functions of ARMS/Kidins220 have not been well elucidated. Specifically, ARMS/Kidins220 acts as a major signaling platform for prolonged MAP kinase signaling by neurotrophins (Arevalo et al., 2004; 2006). ARMS/Kidins220knockdown also decreases the levels of pMAPK and increases neuronal cell death mediated by excitotoxicity in cerebral ischemia (Lopez-Menendez et al., 2009).

ARMS/Kidins220 is colocalized with TrkA on the cell surface of sympathetic neurons in the developing nervous system (Kong et al., 2001). Interestingly, ARMS/Kidins220 expression is highly increased in human melanoma compared to benign skin lesions, and prevents stress-induced apoptosis in melanoma cells by activating ERK pathway (Liao, 2007). Its expression is also increased in human neuroblastoma, another neural crest tumor, and stabilizes NGF-induced survival signaling (Rogers and Schor, 2013). Therefore, similar to Trk receptors which have certain roles as oncogenes (Martin-Zanca et al. 1986), ARMS/Kidins220 may also have the potential to act as an oncogene (Neubrand et al., 2012).

One of the important functions of oncogenes is to increase cell proliferation by stimulating cell-cycle progression. As a tumor suppressor, pRb inhibits cell-cycle progression at $\mathrm{G}_{1} / \mathrm{S}$ by blocking the activity of the E2F family of transcription factors, which activate the genes required for induction of $S$ phase. $\mathrm{Rb}$ function is regulated through cell cycle by phosphorylation (Chen et al., 1989). Hyperphosphorylation of pRb by cyclinCDK complexes in the $G_{1}$ phase inactivates its growth suppression function; consequently, the $\mathrm{G}_{1}$ restriction point in cell cycle is bypassed (reviewed in Malumbres and Barbacid, 2009). p21, one of the CKIs in $G_{1} / S$ transition, was originally identified as a downstream mediator of tumor suppressor p53 (El-Deiry et al., 1993; Harper et al., 1993; Xiong et al., 1993a). Upregulation of p21 inhibits the kinase activity of G1 cyclin/CDK complexes, thus preventing the hyperphosphorylation of $\mathrm{pRB}$ and blocking cell-cycle progression (Dulic et al., 1994).

In this study, ARMS/Kidins220-knockdown induced a slowdown of cell cycle in the $G_{1}$ phase, leading to decreased neuroblastoma cell proliferation. Downregulation of ARMS/ Kidins220 is associated with the decreased expressions of cyclin D1 and CDK4 in the $\mathrm{G}_{1}$ phase but has no effect on other cell-cycle regulatory proteins, such as cyclin $A$, cyclin $E$ and CDK2. Cyclin $D$ is expressed at $G_{1} / S$ transition where diverse mitogenic signaling cascades are converged to mediate engagement of the cell cycle machinery. Thus, cyclin D1 is often overexpressed and associated with tumorigenesis in many cancers (Masamha and Benbrook, 2009). In some cells, the downstream cyclin $E$ can replace cyclin $D$ to facilitate $G_{1} / S$ transition. But, loss of cyclin $D$ is sufficient to cause $G_{1}$ arrest in other cellular contexts (Masamha and Benbrook, 2009).
Interestingly, even without cell-cycle progression, CDK4 protein level was significantly decreased in ARMS-KD cells. Thus, it is likely that CDK4 activity is consistently inhibited in these cells. We further confirmed that the decreased cyclin D1/CDK4 levels were tightly associated with p21 upregulation at all-time points in our experiment. In contrast, the level of p16 protein, another $\mathrm{CKI}$ in $\mathrm{G}_{1} / \mathrm{S}$ transition, was unchanged in ARMS-KD cells. Indeed, the level of ppRb was also lower in these cells than the controls at $24 \mathrm{~h}$ after the cell-cycle entry.

Consistent with the previous studies, we also observed that ARMS/Kidins220-knockdown decreases pERK level (Arevalo et al., 2004; Liao et al., 2007; 2011). Since ARMS/Kidins220 mediates prolonged MAPK signaling by interacting with CrkL (Arevalo et al., 2004; 2006), it will be interesting to examine which adaptor(s) or effector(s) is (are) involved in ARMS/ Kidins220-p21 pathway for cell-cycle regulation. Identifying the specific domain of ARMS/Kidins220 involved in the regulation of p21 expression using the serial deletion constructs of ARMS/Kidins220 will be useful to further delineate this pathway. The other interesting question to address will be whether ARMS/Kidins220 is also involved in other tumor cells and normal cell proliferation by the same mechanism demonstrated in our study. Although the tumor suppressor role of p21 is still controversial (reviewed in Besson et al., 2008), it is clear that p21 inhibits cyclinD1/CDK4, which results in retarded cell proliferation in this study.

In summary, we demonstrate that ARMS/Kidins220 regulates the neuroblastoma cell proliferation through p21 protein. Our results suggest that ARMS/Kidins220 acts as an important platform in organizing the signaling complex to regulate cellcycle progression in response to the extracellular stimuli. In addition, as a potential oncogene, ARMS/Kidins220 may serve as an important prognostic factor of tumors in the nervous system.

Note: Supplementary information is available on the Molecules and Cells website (www.molcells.org).

\section{ACKNOWLEDGMENTS}

We would like to thank Prof. Sunyoung Kim (Department of Biological Sciences, Seoul National University) for his kind help with generation of retroviral vectors. This research was supported by the Basic Science Research Program through the National Research Foundation of Korea (M-SC, 2011-0003075) funded by the Ministry of Education, Science and Technology, and by a grant of the Korean Health Technology R\&D Project (M-SC, A120476), Ministry of Health \& Welfare, Republic of Korea.

\section{REFERENCES}

Arevalo J.C., Yano H., Teng K.K., and Chao M.V. (2004). A unique pathway for sustained neurotrophin signaling through an ankyrinrich membrane-spanning protein. EMBO J. 23, 2358-2368.

Arevalo J.C., Pereira D.B., Yano H., Teng K.K., and Chao M.V. (2006). Identification of a switch in neurotrophin signaling by selective tyrosine phosphorylation. J. Biol. Chem. 281, 1001-1007.

Arevalo, J.C., Wu, S.H., Takahashi, T., Zhang, H., Yu, T., Yano, H., Milner, T.A., Tessarollo, L., Ninan, I., Arancio, O., et al. (2010). The ARMS/Kidins220 scaffold protein modulates synaptic transmission. Mol. Cell Neurosci. 45, 92-100.

Baldin, V., Lukas, J., Marcote, M.J., Pagano, M., and Draetta, G. (1993). Cyclin D1 is a nuclear protein required for cell cycle progression in G1. Genes Dev. 7, 812-821.

Bates, S., Parry, D., Bonetta, L., Vousden, K., Dickson, C., and Peters, G. (1994). Absence of cyclin D/cdk complexes in cells lacking functional retinoblastoma protein. Oncogene 9, 1633-1640. 
Besson, A., Dowdy, S.F., and Roberts, J.M. (2008). CDK inhibitors: cell cycle regulators and beyond. Dev. Cell 14, 159-169.

Bracale A., Cesca F., Neubrand V.E., Newsome T.P., Way M., and Schiavo G. (2007). Kidins220/ARMS is transported by a kinesin1-based mechanism likely to be involved in neuronal differentiation. Mol. Biol. Cell 18, 142-152.

Brummelkamp, T.R., Bernards, R., and Agami, R. (2002). Stable suppression of tumorigenicity by virus-mediated RNA interference. Cancer Cell 2, 243-247.

Cesca F., Yabe A., Spencer-Dene B., Scholz-Starke J., Medrihan L., Maden C.H., Orriss I.R., Baldelli P., AI-Qatari M., Koltzenburg M., et al. (2012). Kidins220/ARMS mediates the integration of the neurotrophin and VEGF pathways in the vascular and nervous systems. Cell Death Differ.19, 194-208

Chang, M.S., Arevalo, J.C., and Chao, M.V. (2004). Ternary complex with Trk, p75, and an ankyrin-rich membrane spanning protein. J. Neurosci. Res. 78, 186-192.

Chao, M.V. (2003). Neurotrophins and their receptors: a convergence point for many signalling pathways. Nat. Rev. Neurosci. 4, 299-309.

Chen, P.L., Scully, P., Shew, J.Y., Wang, J.Y., and Lee, W.H (1989). Phosphorylation of the retinoblastoma gene product is modulated during the cell cycle and cellular differentiation. Cell 58, 1193-1198.

Chen Y., Fu W.Y., Ip J.P., Ye T., Fu A.K., Chao M.V., and Ip N.Y. (2012). Ankyrin repeat-rich membrane spanning protein (kidins220) is required for neurotrophin and ephrin receptordependent dendrite development. J. Neurosci. 32, 8263-8269.

Cortes R.Y., Arevalo J.C., Magby J.P., Chao M.V., and Plummer M.R. (2007). Developmental and activity-dependent regulation of ARMS/Kidins220 in cultured rat hippocampal neurons. Dev. Neurobiol. 67, 1687-1698.

Dulic V., Kaufmann W.K., Wilson S.J., Tlsty T.D., Lees E., Harper J.W., Elledge S.J., and Reed S.I. (1994). p53-dependent inhibition of cyclin-dependent kinase activities in human fibroblasts during radiation-induced G1 arrest. Cell 76, 1013-1023.

Duffy A.M., Schaner M.J., Wu S.H., Staniszewski A., Kumar A., Arevalo J.C., Arancio O., Chao M.V., and Sharfman H.E. (2011). A selective role for ARMS/Kidins220 scaffold protein in spatial memory and trophic support of entorhinal and frontal cortical neurons. Exp. Neurol. 229, 409-420.

El-Deiry W.S., Tokino T., Velculescu V.E., Levy D.B., Parsons R., Trent J.M., Lin D., Mercer W.E., Kinzler K.W., and Vogelstein B. (1993). WAF1, a potential mediator of p53 tumor suppression. Cell 75, 817-825.

Furuno N., den Elzen N., and Pines J. (1999). Human cyclin A is required for mitosis until mid prophase. J. Cell Biol. 147, 295306.

Harper J.W., Adami G.R., Wei N., Keyomarsi K., and Elledge S.J. (1993). The p21 Cdk-interacting protein Cip1 is a potent inhibitor of G1 cyclin-dependent kinases. Cell 75, 805-816.

Higuero, A. M., Sanchez-Ruiloba, L., Doglio, L. E., Portillo, F., AbadRodriguez, J., Dotti, C.G., and Iglesias, T. (2010). Kidins220/ ARMS modulates the activity of microtubule-regulating proteins and controls neuronal polarity and development. J. Biol. Chem. $285,1343-1357$.

Iglesias T., Cabrera-Poch N., Mitchell M.P., Naven T.J., Rozengurt E., and Schiavo G. (2000). Identification and cloning of Kidins220, a novel neuronal substrate of protein kinase D. J. Biol. Chem. 275, 40048-40056.

Jadhav, U., Ezhilarasan, R., Vaughn, S.F., Berhow, M.A., and Mohanam, S. (2007). Iberin induces cell cycle arrest and apoptosis in human neuroblastoma cells. Int. J. Mol. Med. 19, 353361.

Jiao, W., Datta, J., Lin, H.M., Dundr, M., and Rane, S.G. (2006). Nucleocytoplasmic shuttling of the retinoblastoma tumor suppressor protein via Cdk phosphorylation-dependent nuclear export. J. Biol. Chem. 281, 38098-38108.
Kong, H., Boulter, J., Weber, J.L., Lai, C., and Chao, M.V. (2001). An evolutionarily conserved transmembrane protein that is a novel downstream target of neurotrophin and ephrin receptors. J. Neurosci. 21, 176-185.

Li, J., Chen, L. A., Townsend, C. M., Jr., and Evers, B.M. (2008). PKD1, PKD2, and their substrate Kidins220 regulate neurotensin secretion in the BON human endocrine cell line. J. Biol. Chem. 283, 2614-2621.

Liao, Y.H., Hsu, S.M., and Huang, P.H. (2007). ARMS depletion facilitates UV irradiation induced apoptotic cell death in melanoma. Cancer Res. 67, 11547-11556.

Liao, Y.H., Hsu, S.M., Yang, H.L., Tsai, M.S., and Huang, P.H. (2011). Upregulated ankyrin repeat-rich membrane spanning protein contributes to tumour progression in cutaneous melanoma. Br. J. Cancer 104, 982-988.

Lopez-Menendez, C., Gascon, S., Sobrado, M., Vidaurre, O.G., Higuero, A.M., Rodriguez-Pena, A., Iglesias, T., and Diaz-Guerra, M. (2009). Kidins220/ARMS downregulation by excitotoxic activation of NMDARs reveals its involvement in neuronal survival and death pathways. J. Cell Sci. 122, 3554-3565.

Malumbres, M., and Barbacid, M. (2009). Cell cycle, CDKs and cancer: a changing paradigm. Nat. Rev. Cancer 9, 153-166.

Martin-Zanca D., Hughes S.H., and Barbacid M. (1986). A human oncogene formed by the fusion of truncated tropomyosin and protein tyrosine kinase sequences. Nature 319, 743-748.

Masamha C.P., and Benbrook D.M. (2009). Cyclin D1 degradation is sufficient to induce G1 cell cycle arrest despite constitutive expression of cyclin E2 in ovarian cancer cells. Cancer Res. 69, 6565-6572.

Neubrand V.E., Thomas C., Schmidt S., Debant A., and Schiavo G. (2010). Kidins220/ARMS regulates Rac1-dependent neurite outgrowth by direct interaction with the RhoGEF Trio. J. Cell Sci. 123, 2111-2123.

Neubrand, V.E., Cesca, F., Benfenati, F., and Schiavo, G. (2012). Kidins220/ARMS as a functional mediator of multiple receptor signalling pathways. J. Cell Sci. 125, 1845-1854.

Park, H.J., Park, H.W., Lee, S.J., Arevalo, J.C., Park, Y.S., Lee, S.P., Paik, K.S., Chao, M.V., and Chang, M.S. (2010). Ankyrin repeat-rich membrane spanning/Kidins220 protein interacts with mammalian Septin 5. Mol. Cells 30, 143-148.

Rogers D.A., and Schor N.F. (2013). Kidins220/ARMS depletion is associated with the neural-to Schwann-like transition in a human neuroblastoma cell line model. Exp. Cell Res. 319, 660-669.

Sherr, C.J. (1995). Mammalian G1 cyclins and cell cycle progression. Proc. Assoc. Am. Physicians 107, 181-186.

Sniderhan, L.F., Stout, A., Lu, Y., Chao, M.V., and Maggirwar, S.B. (2008). Ankyrin-rich membrane spanning protein plays a critical role in nuclear factor-kappa B signaling. Mol. Cell Neurosci. 38, 404-416.

Sutachan J.J., Chao M.V., and Ninan I. (2010). Regulation of inhibitory neurotransmission by the scaffolding protein ankyrin repeatrich membrane spanning/kinase D-interacting substrate of 220 kDa. J. Neurosci. Res. 88, 3447-3456.

Wu S.H., Arevalo J.C., Sarti F., Tessarollo L., Gan W.B., and Chao M.V. (2009). Ankyrin Repeat-rich Membrane Spanning/Kidins220 protein regulates dendritic branching and spine stability in vivo. Dev. Neurobiol. 69, 547-557.

Wu S.H., Arevalo J.C., Neubrand V.E., Zhang H., Arancio O., and Chao M.V. (2010). The ankyrin repeat-rich membrane spanning (ARMS)/Kidins220 scaffold protein is regulated by activitydependent calpain proteolysis and modulates synaptic plasticity. J. Biol. Chem. 285, 40472-40478.

Xiong, Y., Hannon, G.J., Zhang, H., Casso, D., Kobayashi, R., and Beach, D. (1993a). p21 is a universal inhibitor of cyclin kinases. Nature 366, 701-704.

Xiong, Y., Zhang, H., and Beach, D. (1993b). Subunit rearrangement of the cyclin-dependent kinases is associated with cellular transformation. Genes Dev. 7, 1572-1583. 